
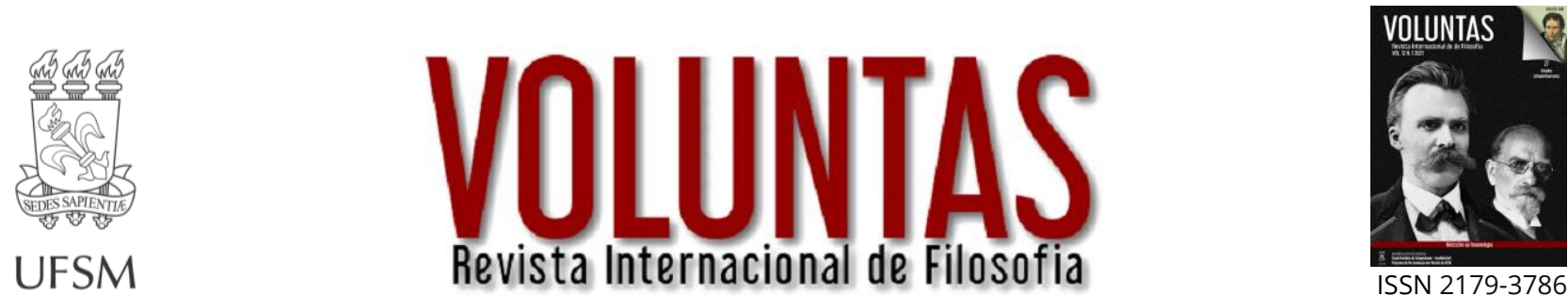

ISSN 2179-3786

๖Acesso aberto

Voluntas, Santa Maria, v.12, n.1, p. 01-30, jan/abril, 2021 • https://doi.org/10.5902/2179378661899

Submissão: 19/10/2020 • Aprovação: 19/04/2021 • Publicação: 05/05/2021

Fluxos contínuos

\title{
A busca schopenhaueriana das identidades fundamentais: a influência platônica
}

\author{
The schopenhauerian pursuit of fundamental identities: the Platonic \\ influence
}

\section{Francisco William Mendes Damasceno'}

' Universidade Estadual do Piauí. Floriano, Piauí, Brasil

\begin{abstract}
RESUMO
Apesar da declaração, por parte do próprio Schopenhauer, de que a sua noção de Ideia deve ser entendida no mesmo sentido da Ideia platônica, estas não são idênticas, e apesar da declarada pretensão de filiação filosófica, é preciso ter em mente as divergências entre essas concepções para bem compreender a noção schopenhaueriana de filosofia como metafísica. Do mesmo modo que Schopenhauer se pretende kantiano mas transforma radicalmente a filosofia transcendental de Kant, o mesmo ocorre com a Ideia platônica na composição da metafísica da Vontade. Dentre as várias influências, as filosofias de Platão e de Kant são o principal material a partir do qual Schopenhauer constrói sua filosofia metafísica. O objetivo do presente artigo, portanto, é mostrar como Schopenhauer, por meio da fusão de certos aspectos das filosofias de Platão e Kant, pensa solucionar as contradições inerentes à teoria platônica das Ideias como identidades puras e, deste modo, manter a noção de Ideia dos diálogos metafísicos enquanto identidades que sustentam a possibilidade de uma epistemologia no sentido do discurso racional científico-filosófico e das consequências que daí advém.
\end{abstract}

Palavras-chave: Ideia; Racionalidade; Representação

\section{ABSTRACT}

Despite of Schopenhauer's statement that his notion of Idea is to be understood in the same sense as the Platonic Idea, these are not identical, and despite the declared pretension of philosophical affiliation, it is necessary to have in mind the divergences between these conceptions to well understand the Schopenhauerian notion of philosophy as metaphysics. In the same way that Schopenhauer intends to be Kantian but transforms radically the transcendental philosophy of Kant, so does the Platonic Idea in the composition of the metaphysics of Will. Among the various influences, the philosophies of Plato and Kant are the main material from which Schopenhauer builds his metaphysical philosophy. The aim of this article, therefore, is to show how Schopenhauer, through the fusion of certain aspects of the 
philosophies of Plato and Kant, intends to solve the contradictions inherent in the Platonic theory of Ideas as pure identities and thus maintain the notion of Idea of metaphysical dialogues as identities that support the possibility of an epistemology in the sense of rational scientific-philosophical discourse and the consequences that follows.

Keywords: Idea; Rationality; Representation

\section{INTRODUÇÃO}

A teoria das Ideias parece ser de fato o centro da filosofia platônica, pelo menos dos seus Diálogos, a chamada doutrina exotérica. A partir dos chamados Diálogos intermediários, momento em que Platão mostra-se mais independente de seu mestre e passa a expor suas próprias teorias, utilizando-se, nos Diálogos, do personagem Sócrates mais como seu porta-voz. Surge, então, a célebre concepção de um mundo inteligível que fundamenta o sensível. No entanto, tal teoria parece ser objeto de debates e controvérsias intermináveis entre os especialistas da filosofia platônica. A construção de uma sistematização coerente entre as diversas fases do pensamento platônico e as diferentes, e até divergentes, formulações da teoria das Ideias, tem se colocado como um desafio talvez insuperável para aqueles que se dedicam ao estudo da metafísica antiga. Em relação à interpretação da metafísica platônica, e às possíveis contradições das distintas teorias das Ideias que aparecem na obra de Platão, parece existir de modo geral, duas posições, que estão didaticamente expostas em linhas gerais na obra de Giovanni Reale, intitulada Para uma nova interpretação de Platão. Reale, como é de se esperar, posiciona-se no debate e desenvolve a obra citada segundo sua posição, favorável à Escola de Tübingen. ${ }^{1}$

A nosso ver, o principal problema enfrentado pelos intérpretes de Platão, de onde surgem, do ponto de vista de uma unidade do pensamento platônico, todas as contradições referentes à teoria das Ideias, é o que parece ser uma crítica de Platão à sua própria teoria das Ideias. Encontramos a mencionada crítica no Diálogo Parmênides, situado na passagem da fase dos grandes Diálogos metafísicos para a fase dos Diálogos tardios. Neste diálogo, os interlocutores não chegam a uma conclusão clara acerca da

\footnotetext{
1 Para maiores detalhes, ver: REALE, Para uma nova interpretação de Platão.
} 
"natureza" do Ser, o qual é agora não apenas Uno mas também múltiplo. Ao longo do texto, o "Sábio" Parmênides conduz o jovem e inexperiente Sócrates pelas consequentes aporias a que se é levado pela crença na teoria das Ideias contida nos Diálogos precedentes, teoria que se funda num princípio de identidade restrito e, ao que tudo indica, insustentável. As Ideias, como são definidas no Fédon e em outros diálogos intermediários, são realidades imateriais existentes em-si e por-si, de modo que cada Ideia é uma identidade pura, cuja existência é determinada apenas por si mesma. Enquanto os seres sensíveis têm sua existência dependente da sua participação nas Ideias e das inter-relações que mantêm entre si, sendo cada um sempre "por outros" e não "por si" mesmo, não sendo de fato, pois "é" propriamente apenas aquilo que depende apenas de si para ser. As Ideias, por outro lado, sendo sempre por si e sempre idênticas a si, "são" verdadeiramente. É justamente este princípio de identidade pura que determina a si mesma que, a partir do diálogo Parmênides, é colocado em questão. Entretanto, essa crítica encontrará seu complemento no diálogo Sofista, onde o Estrangeiro defende que as meta-ideias (ou gêneros supremos para alguns) elencadas (ser, movimento, repouso, mesmo e outro) participam umas das outras. Mostra-se que o "não-ser" é, participando assim da Ideia de "Ser", enquanto, por outro lado, o Ser não é, pois não sendo nenhum ser particularmente e nem a totalidade, coloca-se como o outro de todos aqueles que não ele mesmo, não sendo infinitas vezes por participar da ideia de "outro". Assim termina Platão o Diálogo Sofista:

Estrangeiro.- (...) Há uma associação mútua dos seres. O ser e o outro penetram através de todos e se penetram mutuamente. Assim, o outro, participando do ser, é, pelo fato de participação, sem, entretanto, ser aquilo de que participa, mas o outro, e por ser outro que não o ser, é, por manifesta necessidade, nãoser. O ser, por sua vez, participando do outro, será pois, outro que não o resto dos gêneros. Sendo outro que não eles todos, não é, pois, nenhum deles tomado à parte, nem a totalidade dos outros, mas somente ele mesmo; de sorte que o ser, incontestavelmente, milhares e milhares de vezes não é, e os outros, seja individualmente, seja em sua totalidade, são sob múltiplas relações, e, sob múltiplas relações não são. ${ }^{2}$

2 PLATÃO. Sofista. 259 a - b.

Voluntas, Santa Maria, v.12, n.1, p. 01-30, jan/abril, 2021 
No Parmênides, a crítica põe a possibilidade de que a existência dos inteligíveis possa estar submetida às mesmas relações de participação encontradas no sensível, onde as unidades concretas ou seres sensíveis, por participação nas diferentes Ideias e pela sua natureza relativa, têm sua existência dependente de relações e são ao mesmo tempo unas e múltiplas. Também as Ideias, seres inteligíveis, terão sua identidade determinada a partir das relações que mantêm entre si. Para Platão, o problema não é apenas uma questão da linguagem, mas um problema ontológico. Pode-se pensar e "dizer" o "ser", ou seja, conhecer, porque a alma e as Ideias que formatam os fenômenos sensíveis compartilham a mesma natureza inteligível, o mesmo logos; portanto, as contradições da linguagem correspondem a contradições inerentes ao próprio real, seja ele sensível ou inteligível. Na posterior formulação das Ideias, encontrada no Sofista, parece haver uma aproximação maior entre os planos sensível e inteligível, mesmo as Ideias permanecendo superiores na hierarquia da existência. Mas agora considera-se que a identidade das Ideias é determinada pelas relações que elas mantêm ao participarem umas das outras. Também a existência desses seres inteligíveis é agora considerada como formada de relações. A identidade, em qualquer plano é, nesta consideração, determinada pela alteridade, por meio da relação entre os contrários. Mas por que abrir mão da noção de identidades puras que se determinam a si mesmas? Simplesmente porque, obviamente, tal coisa é inaceitável para a razão. Algo que determina a si mesmo é algo indeterminado, algo que se diz por si mesmo é indizível. Se as Ideias forem de tal tipo, elas simplesmente não são, portanto, são não-ser, o que seria inaceitável, pois o que a teoria pretende, seja a anterior aos diálogos intermediários ou a encontrada nos diálogos tardios, é justamente que tais arquétipos sejam o Ser propriamente, em grau maior, mesmo que participando também do não-ser pela relatividade da sua identidade.

A fundamentação da identidade na alteridade vem justamente tentar superar a indeterminação e o retrocesso ${ }^{3}$ ao infinito que o pensamento da identidade pura

\footnotetext{
${ }^{3}$ Esta crítica à concepção das Ideias como unidades isoladas, identidades autofundantes, torna-se célebre pela expressão de Aristóteles, "argumento do terceiro homem". Esta crítica aparece repetida de
} 
estabelece no conhecimento. Tratando a questão de um ponto de vista lógico ou linguístico, o problema é o seguinte: O conceito de "Homem", por exemplo, não se diz ou se faz entender por si mesmo. Dizer "o homem é homem" e dizer "O homem", é o mesmo, e nada foi dito, já que o predicado que utilizo para determinar, delimitar, ou definir o conceito não está, ele mesmo, determinado, pois é este mesmo conceito que tento definir como sujeito buscando seus predicados. Precisamos antes significar, determinar o predicado por meio de seus predicados para que o primeiro possa significar o sujeito estabelecendo sua definição. Porém, se estabelecemos por princípio que cada conceito é dito ou significado apenas por si mesmo (o que acontece com as Ideias se as consideramos identidades puras), este processo recai num retorno infinito, no qual os conceitos-predicados que determinam o primeiro conceito-sujeito, nas relações que mantêm com seus próprios predicados, permanecem sempre indefinidos, o que leva à total indeterminação dos termos e à impossibilidade do conhecimento, enquanto função da razão que opera pelos princípios lógicos fundamentais. Deste modo, a definição de um conceito é construída, estabelecida, determinada, definida ou delimitada, pelos conceitos que se relacionam com ele como seus predicados na proposição, do mesmo modo que, do ponto de vista ontológico, a identidade dos seres é dada pelas qualidades que se relacionam com a substância como atributos. A partir do Parmênides, este problema acerca da identidade e da relação entre as Ideias (formas) é claramente tematizado. Acerca disso nos diz Victor Goldschimidt:

\footnotetext{
forma mais ou menos variada pelos comentadores, tanto antigos quanto contemporâneos. Victor Goldschmidt faz referência a este argumento na seguinte passagem: "Sem entrar nos detalhes das críticas pelas quais Parmênides mostra as consequências insustentáveis da teoria das Formas, pode-se notar que as Formas são tratadas como imagens. O argumento dito do terceiro homem, em particular, não faz senão retomar, contra as Formas, o argumento et alia. É próprio de toda coisa sensível não ser jamais a única a figurar o objeto. (...). Mas a dignidade da Forma quer que ela seja a única a ser o que ela é. A quem perguntar por que Deus não criou duas camas, basta responder: 'Porque se fizesse apenas duas, manifestar-se-ia nelas uma terceira, cuja Forma as duas reproduziriam, e seria ela a cama essencial, e não as duas outras. Deus, sabendo disso, suponho, e querendo ser o criador de uma cama real, e não o fabricante particular de uma cama particular, criou esta cama única por natureza'. (...). A forma é única porque ela o 'quer' assim, porque, múltipla, ela não se distinguiria em nada das imagens. (...). - Ora, o argumento do terceiro homem transpõe o argumento et alia ao mundo das formas. Com que direito a Grandeza em si pretende ser tal e, por conseguinte, única, ela que vê contestar esse título pela multidão de grandezas sensíveis? Basta interpretar a Forma ad modum imaginis para conduzi-la à mesma aporia da imagem" (GOLDSCHMIDT, Os diálogos de Platão, 137).
} 
Comparados ao problema do Parmênides, que é o problema do Ser, todos os problemas considerados nos diálogos precedentes não são senão casos de aplicação. O Parmênides põe o problema por excelência, o problema do Ser absolutamente, não mais de tal ser (beleza, sabedoria, coragem. Ora, todos esses seres diferenciados, em relação à multiplicidade das imagens, eram, cada um, “um"). ${ }^{4}$

(...) Mas o que Sócrates pede a Zenão, a respeito das Formas, é mostrar agora esse jogo de oposição e de implicação. Talvez, porém, isto Sócrates não o diga, o um-múltiplo das Formas possa nos conduzir a uma nova, a uma última unidade, a uma unidade essencial, desta vez, como o um-múltiplo das imagens reduzira-se à unidade das Formas. - Mas não parece que Sócrates considere a tarefa possível. (...) no espírito de Sócrates é contraditório que as Formas, essencialmente unas, possam revelar-se múltiplas. ${ }^{5}$

Entretanto, a concepção de uma teoria que aceita a comunhão ou participação das Ideias entre si, a fim de solucionar o grave problema da fundamentação da identidade das Ideias, ou do ser da Ideias, traz consigo outros problemas igualmente graves. A participação das ideias entre si visa a solucionar, de certo modo, dois problemas da primeira concepção: 1) primeiramente, o retorno ao infinito, presente na teoria das Ideias dos Diálogos intermediários, que fundamentava a identidade e unidade de cada Ideia em sua própria identidade na relação isolada consigo mesma, o que levava a uma regressão infinita pela necessidade de repor incessantemente um terceiro termo, que por ser sempre o si mesmo, de saída indeterminado, não era capaz de determinar o seu ser próprio. Do ponto de vista do discurso, ou seja, da razão, nenhuma definição é alcançada, o ser permanece impensável por conceitos, portanto, indizível. Mas aquilo que "é" deveria poder ser dito, já que há uma continuidade entre a alma e o ser inteligível das coisas. Esta fundamentação pela identidade emudece a alma, impossibilitando, assim, a ciência. 2) Em segundo lugar, há um problema semelhante ao primeiro, com a diferença de que no primeiro a relação era horizontal, das Ideias entre si. Agora, trata-se da relação vertical das Ideias com suas imagens, seres sensíveis que existem seja por imitação ou por participação nas Ideias. Este problema da relação é posto em ambos os sentidos pelo "argumento do terceiro homem". Nesta relação vertical, o problema consiste em que conhecemos os seres

\footnotetext{
${ }^{4}$ GOLDSCHIMIDT, Os diálogos de Platão, 137.

${ }^{5}$ GOLDSCHIMIDT, Os diálogos de Platão, 138.
}

Voluntas, Santa Maria, v.12, n.1, p. 01-30, jan/abril, 2021 
sensíveis pela semelhança com seu modelo ideal. Esta semelhança exige uma comparação com um terceiro termo, um segundo modelo ou Ideia. Na tese dos grandes Diálogos, esse terceiro termo seria o "si mesmo" da Ideia que se determina isolada e que leva à regressão ao infinito e à ilimitação e indeterminação da Ideia e da sua imagem, cópia sensível.

Segundo a interpretação que estamos expondo, o Platão dos Diálogos tardios, para resolver essa questão, parece abandonar o princípio de identidade pura e passa a conceber como fundamento da Identidade não mais a própria identidade, mas a diferença. As Ideias não são capazes de determinar a si por si mesmas isoladamente. A relação que torna possível a sua identidade, o seu ser, é a que mantém com a multiplicidade de Ideias diferentes. Assim, o terceiro termo, segundo modelo, que permite a comparação entre a Ideia e sua cópia sensível, é outra Ideia, ou outras Ideias, que participam da Ideia modelo (primeiro termo) em cada caso particular. Essas Ideias são aquelas que, numa relação horizontal, se interpenetram, fazendo de cada Ideia una e múltipla, fundamentando a existência contraditória dos seres sensíveis na própria contraditoriedade essencial dos seres inteligíveis. O objeto sensível pode ser comparado ao seu modelo ideal pela intermediação das Ideias que participam e determinam a Ideia modelo em questão, e que estão concretizadas na cópia sensível como seus atributos, que por sua vez são também cópias dessas ideias subordinadas e são ditos na linguagem como seus predicados. No Platão tardio, as Ideias, sendo unas e múltiplas, aproximam-se da realidade sensível, que já desde o início da concepção do dualismo ontológico têm um caráter contraditório. Mas é justamente essa contraditoriedade contida na multiplicidade, e na diferença, que torna possível, do ponto de vista ontológico, a determinação dos seres, e, do ponto de vista lógico, a sua definição, e a partir dessa o discurso, possibilitando o conhecimento.

As ideias são, nesta consideração, unas e múltiplas. A multiplicidade implica ou relaciona-se a um certo tipo de mobilidade. No entanto, as Ideias têm de permanecer imóveis e idênticas a si para que assim possam ser fundamento daquilo que se move, que é mutável, corruptível, ou seja, o sensível. As Ideias precisam da estabilidade e 
imobilidade para servir de fundamento ontológico e condição do conhecimento. A crítica da teoria das Ideias, contida no Parmênides e no Sofista, enquanto tenta superar o retorno ao infinito causado pela fundamentação na identidade pura, cria, por outro lado, um novo retorno ao infinito, pois as relações de determinação entre as Formas, apesar da vantagem de tornar possível a constituição da identidade dos seres por meio de atribuições, remete essas relações a um ciclo interminável de novas relações, mesmo estas sendo entre diferenças. Assim, cada Ideia que se coloca como terceiro termo estabelecendo a relação entre dois primeiros, delimitando o ser do que "é", por participação, seja este ser inteligível ou sensível, e, por meio desses limites, fornecendoIhe a existência, cada uma, dizíamos, por sua vez, precisa ser uma identidade determinada que recebe sua determinação de outras identidades igualmente dependentes de outras participações, de modo que este processo também retrocede ao infinito. Acontece, então, que se produz uma crescente de relações infintas entre os dois termos que são comparados, sem que se encontre uma primeira determinação a partir da qual se inicie o processo de significação.

Seja entre duas Ideias, relação horizontal, seja entre uma Ideia e sua imagem sensível, relação vertical, surge uma infinidade de Formas que estabelecem uma distância infinita entre os dois termos. Deste modo, enquanto não pode se fundamentar no princípio de identidade pura, e ao mesmo tempo não encontra apoio num princípio de participação que leva ao relativismo absoluto e igualmente indeterminado, o pensamento encontra-se paralisado. Estas aporias relativas ao conhecimento parecem ser o que leva Platão, segundo alguns intérpretes, a considerar os números irracionais como o indício de que há por trás do Ser que se conhece pela razão um fundamento irracional para além da razão humana. Mas isso quebraria a continuidade pretendida entre a alma e o Ser. Um aprofundamento desse problema seria um desvio do nosso objetivo, portanto, não entraremos em mais detalhes e seguiremos adiante.

Estes desafios com que se depara a filosofia platônica são relevantes para nós, não apenas por estarem presentes em Platão, que de fato se põe como paradigma de 
toda a filosofia acadêmica - se não como paradigma, concederemos que se põe no mínimo como pressuposto, mesmo que implícito, das construções filosóficas, seja para afirmar ou para negar a matriz platônica - mas tais problemas são relevantes também porque, ao resolvê-los a seu modo, Schopenhauer expressa sua concepção de Filosofia, em seu sentido próprio, ou na sua forma mais elevada, como teoria e metafísica.

Como já mencionado, a crítica à teoria das Ideias, que encontramos no Diálogo Parmênides, divide, em linhas gerais, os pesquisadores da filosofia platônica em dois grupos. O critério da divergência é a aceitação ou não de que de fato há uma crítica de Platão à sua própria teoria no mencionado diálogo. Giovanni Reale ${ }^{6}$ posiciona-se no debate em favor do que ele chama de novo paradigma, defendendo a tese de que não há uma crítica de Platão à teoria das Ideias encontrada nos Diálogos intermediários; o que a princípio parece uma crítica seria na verdade um exercício dialético que comporta aporias que são solucionadas em outro nível. Segundo Reale:

No Parmênides, Platão não faz uma autocrítica da própria doutrina das Ideias, mas expõe algumas das principais críticas apresentadas pelos que a contestavam, para oferecer, logo em seguida, uma perspectiva que leva ao postulado superior, ou seja, ao postulado que conduz justamente aos princípios, segundo o esquema apresentado expressamente no Fédon, como já observamos acima. ${ }^{7}$

A hipótese de Reale é que, ao contrário do que pensam os defensores do que ele chama "antigo paradigma", não haveria uma evolução do pensamento platônico e nem um abandono, por parte de Platão, em pensar as Ideias como unidades puras existentes em si e por si, ou seja, realidades objetivas cuja existência não depende senão de si mesmas. Segundo esta hipótese, a aparente contradição entre as diversas formulações da teoria das Ideias seriam apenas modos distintos de comunicar uma

\footnotetext{
6 Para expor essa divergência entre as interpretações da doutrina de Platão, e exemplificar os argumentos de um dos dois grupos em disputa, aquele que atribui uma maior importância às fontes indiretas e à suposta doutrina esotérica dos Princípios, nos utilizaremos da mencionada obra de Reale, por considerar que se trata de uma pesquisa densa e que, ao mesmo tempo, fornece uma rica fonte para uma introdução ao debate.

${ }^{7}$ REALE, Para uma nova interpretação de Platão, 121.
}

Voluntas, Santa Maria, v.12, n.1, p. 01-30, jan/abril, 2021 
doutrina fundamental mais importante não contida nos escritos, sendo, portanto, uma doutrina esotérica. Esta, segundo Reale, é a teoria dos princípios:

esta evolução da teoria das Ideias, que se encontra nos diálogos, refere-se não tanto à evolução da doutrina, mas, antes, ao modo de comunicá-la e ao modo de expor por escrito algumas relações que ela tem com a teoria dos princípios. $^{8}$

Para outros intérpretes, no entanto, encontra-se no Parmênides, de fato, uma crítica da teoria que atesta, sim, uma evolução ou alteração do pensamento de Platão. Assim, nem tudo aquilo que encontramos no final ou ao longo da sua obra estaria já desde o início formulado por Platão. Certas doutrinas, como a dos princípios, seriam concebidas em reformulações das teses metafísicas, sem, no entanto, se constituírem como um conhecimento esotérico negado aos escritos por sua demasiada importância. Acerca disso nos fala G. Figal ${ }^{9}$ em um artigo publicado como resposta à interpretação de Reale da filosofia platônica, e que encontra-se como apêndice da obra citada:

Para o problema da relação entre diálogos intermediários e a obra mais tardia, o Parmênides é de particular interesse: aqui a cisão parece mostrar-se de maneira particularmente clara, por meio da dura crítica à doutrina das Ideias articulada pelo jovem Sócrates. (...). É claro que Reale, com base nos próprios pressupostos, não pode ler como autocrítica platônica a crítica de Parmênides à concepção socrática das Ideias, que Platão levanta por um jogo: “um divertimento do espírito para quem compreendeu o justo sentido da doutrina das Ideias"(375). ${ }^{10}$

\footnotetext{
${ }^{8}$ REALE, Para uma nova interpretação de Platão, 119.

9 "G. Figal é professor de filosofia na Universidade de Tübingen (mas proveniente de Heidelberg e é aluno de W. Wieland) e diretor (com E. Rudolph) da revista citada na nota precedente. A sua obra mais recente intitula-se Für eine Philosophie von Freiheit und Streit. Politik - Ästhetik - Metaphysik, Stuttgar-Weimar 1994." (Nota de rodapé em: REALE, Para uma nova interpretação de Platão, 573).

${ }^{10}$ REALE, Apêndice VI: Discussões de G. Figal com resposta de Reale. LUTA DE GIGANTES. Para uma nova interpretação de Platão, 577.
}

Voluntas, Santa Maria, v.12, n.1, p. 01-30, jan/abril, 2021 
Em outra passagem:

Há quem considere impossível levar a uma conexão objetivamente plausível os pensamentos expostos nos diálogos de Platão, enquanto assume em Platão como faz Hermann Schmitz - diversas doutrinas das Ideias irreconciliáveis entre si; há os que só podem explicar - como os defensores da história evolutiva - a plausibilidade da conexão dos textos recorrendo a uma biografia intelectual; há quem leia - como Wolfgang Wieland - os textos como apresentações exemplares de um saber implícito, na sua essência prático: todos esses não são incondicionalmente predestinados a favor da tentativa de persuasão operada por Reale. Contudo, mesmo quem vê que as perspectivas interpretativas citadas, em todas as suas posições, deixam questões abertas, quem por isso experimenta curiosidade e se deixa dirigir a palavra, não está ainda incondicionalmente disposto a dar o passo na direção do novo paradigma. ${ }^{11}$

Pelas passagens citadas acima, percebemos que não há entre os especialistas uma concordância geral acerca das doutrinas platônicas. Há inclusive quem duvide que a filosofia platônica possa ser sistematizada, ou que as contradições ou aporias que encontramos na obra possam ser solucionadas ou conciliadas. Visto desta perspectiva, não surpreende que a Academia de Platão tenha seguido em direção ao ceticismo quando assumida por seus discípulos. Temos de mencionar que também não é nosso objetivo aqui propor soluções para as citadas questões em disputa.

Esse debate acerca da existência de divergentes teorias das Ideias entre as fases do pensamento platônico interessa-nos apenas na medida em que percebemos na metafísica schopenhaueriana uma forte influência de Platão e que a interpretação feita por Schopenhauer mantém, na perspectiva ontológica, mesmo que à luz da filosofia transcendental kantiana, a noção de "ser verdadeiro" como identidades puras multiplicadas no fenômeno, ao mesmo tempo que mantém, numa perspectiva epistemológica, a relatividade na fundamentação do conhecimento do fenômeno.

Esta metafísica que se enraíza no Platão dos Diálogos intermediários, em que o "ser verdadeiro" são formas eternas e imutáveis, conduzirá à consideração de que no mundo fenomênico, no mundo como representação, é impossível a liberdade e a felicidade, e ao pessimismo presente em seu pensamento.

\footnotetext{
${ }^{11}$ REALE, Apêndice VI: Discussões de G. Figal com resposta de Reale. LUTA DE GIGANTES. Para uma nova interpretação de Platão, 575.
}

Voluntas, Santa Maria, v.12, n.1, p. 01-30, jan/abril, 2021 
A filosofia schopenhaueriana, de base platônica e kantiana, que toma por objeto ora o em-si dos fenômenos, ora as condições de possibilidade dos fenômenos, é, como declara o próprio Schopenhauer, teoria metafísica. Para o nosso filósofo, toda filosofia, enquanto se pretende filosofia, não pode ser outra coisa senão metafísica, sua dignidade está justamente em tratar do conhecimento do que "verdadeiramente é", a realidade essencial do mundo.

Podemos dizer que, dentro da própria obra de Schopenhauer, esta é a filosofia em sua forma canônica, mas não a única. Aos olhos de alguns de seus intérpretes estaremos sendo um tanto "hereges", e, se pudesse nos ouvir, talvez nosso filósofo ranzinza nos repreenderia por tal afirmação. No entanto, nossa temeridade provém da leitura dos próprios escritos capitais de Schopenhauer. Nos Complementos, encontramos uma outra noção de filosofia, que não apenas é posta paralelamente ao que chamamos aqui de "sua forma canônica", metafísica, como também conecta-se com ela de forma subordinada, intermediando a relação entre a metafísica e as ciências.

Schopenhauer não expõe os problemas da metafísica platônica do modo como fizemos aqui. Também não se inclui no grupo dos especialistas que disputam a possibilidade de uma sistematização dos Diálogos platônicos, apesar do debate, pelo que vimos, ser bem antigo. Na verdade, apesar de colocá-lo em um patamar privilegiado, enxerga Platão como todos os grandes pensadores ao logo da história do pensamento filosófico, como uma filosofia parcialmente verdadeira que é completada por outros pontos de vista que corrigem seus erros. No caso de Platão, este complemento é Kant. Como nos diz, a Ideia platônica e a coisa-em-si kantiana não são a mesma coisa, diferem em um único aspecto extremamente importante: a Ideia é a coisa-em-si tornada representação, mesmo que na sua forma mais geral. A ideia, como já dito, é a representação de um ato de Vontade determinado, que se conhece pela intuição, portanto, pelas formas da representação, mas isento das formas particulares do princípio de razão.

A Ideia schopenhaueriana tem duas faces, das quais apenas uma se mostra. Ela é a representação puramente intuitiva de um ato de Vontade que se mostra como força 
natural, no mundo inorgânico, e espécie, no mundo orgânico ou biológico; e enquanto tal, é a objetivação de uma qualidade oculta e inexplicável, porque sem fundamento, mas que se mostra segundo as formas do intelecto como qualidade empírica na multiplicidade de fenômenos encadeados nas relações causais. A Ideia, no entanto, jamais é causa ou efeito, mas é aquilo que subjaz a todo fenômeno que somente pode vir a ser pela causalidade.

Sempre permanece algo alheio à explanação, que esta, contudo, sempre pressupõe, a saber, as forças da natureza, o modo determinado de fazer efeito das coisas, a qualidade, o caráter de cada fenômeno, o Sem-Fundamento, independente da forma do fenômeno, do princípio de razão, alheio a esta forma e no entanto nela entrando e aparecendo conforme sua lei, que, entretanto, determina justamente o aparecimento, não aquilo QUE aparece; determina apenas o Como, não o Quê do fenômeno, apenas a forma, não o conteúdo. ${ }^{12}$

Faremos agora uma diferenciação interna ao próprio conceito de Ideia schopenhaueriana. Trata-se de uma análise meramente conceitual, separar duas propriedades que a princípio definem o mesmo conceito de Ideia. A primeira destas propriedades é a característica formal das Ideias, consideradas como protótipos inteligíveis ou formas eternas das coisas, não sujeitas à mudança. Esta propriedade é a que aproxima a Ideia Schopenhaueriana e platônica. A outra propriedade que define a Ideia, e que queremos analisar, é a sua característica de algo sem fundamento, qualidade oculta, que expressa a independência da Ideia em relação às formas particulares do princípio de razão.

O conceito de Ideia refere-se a uma realidade objetiva, um objeto universal, imaterial, que se mostra sob as formas do sujeito na representação como qualidade que compõe o fenômeno, sejam essas as qualidades fundamentais da matéria, as forças naturais, ou, em um grau mais complexo, as espécies dos seres orgânicos. Cada indivíduo de determinada espécie e cada fenômeno do mundo inorgânico é a repetida

12 SCHOPENHAUER, O mundo como vontade e como representação, 182.

Voluntas, Santa Maria, v.12, n.1, p. 01-30, jan/abril, 2021 
materialização de uma Ideia, forma universal metafísica, que, por outro lado, é a representação de uma qualidade oculta sob formas subjetivas, qualidade que enquanto manifestação da coisa-em-si, Vontade, é um querer de certo modo. Cada Ideia, enquanto algo irredutível a qualquer outra coisa, inexplicável e compreendida apenas por si mesma na intuição, é o princípio metafísico que fornece aos fenômenos suas qualidades empíricas. No entanto, todas as qualidades conhecidas são, como todo conhecimento ou representação, dependente das formas do sujeito, e, portanto, tais qualidades não correspondem ao que possam ser em si mesmas independentemente das formas da intuição. Esta limitação nunca pode ser superada, pois entre o em si e o fenômeno, o real e o ideal, jamais haverá identidade. As qualidades percebidas são sempre uma constituição subjetiva, são a aparição de realidades insondáveis sob a forma de conhecimento do sujeito. Se o real, aqui considerado o em-si - em oposição ao meramente objetivo, que como representação, é o ideal -, nunca é conhecido, como não cair num solipsismo e num idealismo absoluto? O que induz a crer que há algo além das "minhas" próprias experiências? O impulso metafísico é dado pela própria experiência, mesmo que ela não nos dê aquilo que induz a crer. $O$ fato de as qualidades percebidas serem inexplicáveis, Sem-fundamento, atesta a existência de realidades para além do entendimento e da razão, pois se o real se restringisse ao mundo como representação a ignorância seria impossível, já que o conhecimento consiste justamente em representar, seja pela intuição do entendimento ou pela abstração da razão, de modo que ser e conhecer se fundiriam - o erro de Platão, considerando a partir da filosofia transcendental, parece ter sido justamente não reconhecer a distinção entre a realidade do ser e a idealidade do fenômeno e de suas formas, distinção feita por Kant - e o mundo seria pura forma sem conteúdo, pois a contribuição do sujeito na constituição do mundo é apenas formal; o conteúdo, no entanto, provém das coisas em si mesmas. 
Por outro lado, não posso admitir que mesmo esses corpos sem vida existem tão somente em minha representação; porém, tenho que conceder-Ihes um SER EM Si de algum tipo, já que eles têm propriedades insondáveis e, devido a estas, atividade eficiente. Mas, se esse caráter insondável das propriedades aponta, de um lado, para algo que existe independentemente do nosso conhecer, de outro, dá a prova empírica de que o nosso conhecer, porque consiste apenas no REPRESENTAR por intermédio de formas subjetivas, fornece meras APARÊNCIAS, não a essência em si das coisas. ${ }^{13}$

Conhecer e representar são processos equivalentes. O mundo como representação, fenomênico, é um mundo de aparências; não que existam apenas aparências, mas porque todo objeto vem a ser apenas sob as formas subjetivas, sem as quais nada pode ser conhecido, representado, permanecendo, portanto, inexistente para a consciência. Se, por outro lado, negamos a identidade entre conhecer e representar, e negamos também a distinção entre o real e o ideal, afirmando uma homologia entre o pensamento e o Ser, temos então que lidar com o problema da natureza relativa do mundo objetivo. Problema enfrentado por Platão na elaboração da sua teoria das Ideias.

Como dissemos, Schopenhauer mantém a noção de Ideia como identidade pura, presente nos Diálogos intermediários de Platão. Se considerarmos uma das mencionadas interpretações da doutrina platônica, aquela que defende uma evolução da teoria das Ideias, percebemos que a reformulação da teoria, para uma fundamentação na relação, surge da impossibilidade de se fundamentar o Ser, que no caso de Platão é o plano inteligível das Ideias, em identidades restritas. Contudo, a suposta solução platônica não consegue superar o problema da indeterminação, que permanece mesmo com a nova teoria que estabelece a participação das Ideias entre si como princípio de determinação da sua identidade. Schopenhauer supera este problema ao tomar como ponto de partida a filosofia transcendental kantiana, que estabelece a diferença radical entre a coisa-em-si e o fenômeno. Para Schopenhauer esta diferença refere-se à separação entre o real e o ideal, entre o ser e a aparência. Numa

\footnotetext{
${ }^{13}$ SCHOPENHAUER, 0 mundo como vontade e como representação, Segundo tomo, 235.
} 
perspectiva ontológica, o Ser schopenhaueriano, ao contrário do platônico ${ }^{14}$, é irracional, impulso cego, e conhecido apenas em um sentido hermenêutico a partir de uma identificação interna entre sujeito cognoscente e sujeito do querer. Hermenêutico porque, como já dito, o conhecimento da própria essência como Vontade, estendido por analogia para o restante dos fenômenos, não se faz, contudo, por um acesso completo à coisa-em-si mesma, pois se dá ainda pela mediação do tempo, forma da representação. Entretanto, não pode ser dito também uma representação se lhe falta a forma do sentido externo (espaço) e/ou um fundamento pelo princípio de razão. É, portanto, um conhecimento único, que não nos dá a coisa-em-si plenamente, mas também não é uma representação. Contudo, tal "milagre" nos fornece a significação do fenômeno, e equivale ao mais próximo que se pode chegar do em-si.

Da perspectiva externa, ou seja, pelos sentidos e pelo intelecto, conhecemos apenas representações, objetivações da coisa-em-si sob as formas subjetivas, e também as qualidades universais destes fenômenos particulares, as Ideias, também representação, mesmo que na sua forma mais geral. As Ideias são a objetivação imediata da coisa-em-si, os seus modos determinados, mas não são a coisa em si propriamente: "As Ideias ainda não manifestam a essência em si, mas apenas o caráter objetivo das coisas"15. Estes atos imediatos da Vontade, coisa-em-si, aparecem na representação como princípios universais partilhados pelos fenômenos variados. As diferenças fundamentais entre as duas noções de Ideia, platônica e schopenhaueriana, que permitem a Schopenhauer, de certo modo, superar o problema da Identidade, são:

\footnotetext{
${ }^{14}$ Sabemos que dentre várias possibilidades de interpretação da filosofia platônica, é possível também uma interpretação em que o Ser no seu núcleo mais fundamental seja algo para além da razão, uma realidade de uma ordem distinta do logos da alma, que por isso não cabe no discurso ou na linguagem. Hipóteses acerca desse ser fundamental não lógico podem ser construídas a partir de passagens dos diálogos e das doutrinas não-escritas, que nos induzem nesse sentido, como o problema acerca da natureza dos números irracionais, que apensar de impossíveis de serem determinados seriam constitutivos das formas determinadas. Os irracionais poderiam ser vistos por Platão como o indício de uma natureza irracional como núcleo do Ser, mais fundamental que as próprias Ideias. No entanto, a hipótese interpretativa que consideramos aqui é a que considera a realidade inteligível das Ideias como o Ser propriamente, que por sua vez é conhecido pela razão constitutiva de ambos, alma e ser, sendo justamente essa identidade de natureza que possibilita a ciência.

${ }^{15}$ SCHOPENHAUER, 0 mundo como vontade e como representação, Segundo tomo, 437.
} 
1) a tese de que as Ideias não são o Ser propriamente, mas a sua objetivação primeira, sua objetidade imediata e adequada, diferenciando-se da coisa-em-si apenas por ser representação; e, 2) por serem as Ideias objetos de um tipo especial de intuição, diferente da intuição do fenômeno, e também não um objeto da razão. Nesse acesso intuitivo imediato (sem a mediação do pensamento, do conceito) às "essenciais" (qualidades inexplicáveis) dos fenômenos reside a fundamentação das identidades necessárias para a existência objetiva e para o discurso científico-filosófico.

Por serem representação, as Ideias podem ser conhecidas, já que conhecer é representar (com a ressalva de que não podemos esperar que tais qualidades metafísicas sejam em si mesmas tais como aparecem a nós na representação. Mas o simples fato de percebermos múltiplas qualidades, mesmo que em si permaneçam um mistério, torna evidente a existência de modos determinados de ser). A Ideia não escapa à relatividade apenas por ser representação intuitiva. Poderia se objetar que as representações intuitivas, como no caso dos fenômenos, têm uma existência relativa, e que o simples fato de algo ser intuído não atribui uma existência não-relativa, muito pelo contrário, cada fenômeno tem sua existência determinada pela relação que mantém com outros fenômenos. Esta natureza relativa é o que define propriamente a natureza dos seres sensíveis, como Platão também expressa. A Ideia, entretanto, não é representação do mesmo modo que o fenômeno, é a intuição pura da forma universal deste. É o ponto de convergência de todas as relações que constituem o fenômeno do qual é forma, sem, contudo, submeter-se a estas relações. O conhecimento das Ideias, como exposto no terceiro livro de $O$ mundo, é alcançado pelo desprendimento do intelecto em relação à vontade individual. Esta alteração no sujeito cognoscente, que passa a puro sujeito do conhecimento, produz uma alteração análoga no objeto, quando então é conhecido na sua plena objetividade, no que ele é essencialmente, para além das relações contingentes.

Na metafísica schopenhaueriana a essência dos seres, entendida como sua forma universal, ou seja, a Ideia, é objetivamente conhecida não pela razão, mas pelo entendimento. A Ideia, ontologicamente, não apenas não é o "Ser" no seu sentido 
próprio, pois é ainda representação, como também não é racional, mas completamente alheia à razão. A /deia é conhecida imediatamente por intuição, ou seja, sem a intermediação da razão e suas formas, os conceitos. Pelos conceitos pensamos o que é conhecido intuitivamente. No entanto, todo conhecimento, excetuando o conhecimento interno acerca do próprio corpo como vontade, como nos diz Schopenhauer, tem sua origem na intuição, seja esta empírica (representações completas dotadas de forma e conteúdo), pura a priori (representação das formas do fenômeno, espaço e tempo), ou a representação do objeto em geral, a Ideia. Segundo Schopenhauer, a distinção entre o conhecimento intuitivo e o abstrato é uma característica fundamental da sua filosofia. Nosso filósofo destaca em vários momentos a extrema importância da razão como faculdade de abstração que permite ao homem sair da consciência imediata do presente - a que todos os outros animais estão presos - e expandir sua consciência para a memória do passado e a expectativa do futuro, tornando possível a deliberação a partir de motivos abstratos e os graus superiores da moralidade e do ascetismo, pelo apoio que a razão fornece à intuição na realização de um modo de vida que se faz pela constância da conduta, que necessariamente exigem a memória em conceitos; como também a ciência e a filosofia, conhecimentos por conceitos. Contudo, nenhum conhecimento pode fundamentar-se apenas em conceitos mas, na sua origem, tem sempre de remeter-se a uma intuição a partir da qual surge como cópia abstrata: "o núcleo mais íntimo de todo real e autêntico conhecimento é uma intuição"16 . As representações intuitivas são completas (SW, III, § 17, 42) e empíricas: completas porque contêm a parte formal e a parte material do fenômeno; empíricas porque não são abstrações, são realidades efetivas que atuam presentemente a partir do estímulo da sensação e sob as formas do entendimento, surgindo como objeto-causa. A intuição, na teoria do conhecimento schopenhaueriana, se define como um conhecimento imediato. Por este termo devemos entender "sem a mediação da razão", independente do pensamento, e para isso devemos especificar o

\footnotetext{
${ }^{16}$ SCHOPENHAUER, 0 mundo como vontade e como representação, Segundo tomo, 86.
} 
que significa pensar. Intuir, no sentido estrito do termo, é perceber fenômenos, é ter presentemente para a consciência um objeto material, uma representação empírica, processo pelo qual o mundo objetivo existe a cada momento presente, a partir da aplicação do entendimento aos dados da sensação. Pensar, por sua vez, é operar com as cópias abstratas (conceitos) produzidas a partir das intuições. O pensamento consiste em relacionar conceitos, quando então recebe o nome de juízos, e relacionar juízos, quando então recebe o nome de inferência ou silogismo. A faculdade de juízo, segundo Schopenhauer, exerce a função de produzir os conceitos a partir da intuição:

Fundamentar imediatamente na intuição a verdade e tais primeiros juízos, destacar tais pedras base da ciência a partir da imensa multidão de coisas reais, é obra da FACULDADE DE JUÍZO, este poder de transmitir correta e exatamente para a consciência abstrata o que foi conhecido intuitivamente. Com isso, a faculdade de Juízo é a intermediária entre o entendimento e a razão, e apenas quando ela, num indivíduo, distingue-se e ultrapassa com seu poder a medida comum é que se pode efetivamente fazer progresso nas ciências. ${ }^{17}$

Os primeiros e mais simples conceitos, quando verdadeiros, remetem diretamente à experiência e nela têm seu fundamento e certeza. Schopenhauer nomeia essas representações abstratas de conceitos concretos, justamente por remeterem-se o mais imediatamente possível à intuição, sem a intermediação de outros conceitos. Sobre esses conceitos primeiros são construídos, por meio de juízos, relações que produzirão conceitos mais complexos, levando à formação também de conceitos abstratos.

Participam do processo de pensamento, ou seja, da manipulação de representações abstratas, duas faculdades, a faculdade de juízo e a razão. A primeira opera na mediação entre as outras duas faculdades cognitivas, o entendimento e a razão, operando duas funções já mencionadas por Kant, e reafirmadas por Schopenhauer. A faculdade de juízo opera, então, como juízo reflexionante, quando elabora os conceitos

\footnotetext{
17 SCHOPENHAUER, O mundo como vontade e como representação, 116.
} 
a partir da intuição, operando também como juízo subsumente, quando, em sentido inverso, busca para o conceito os casos particulares, as intuições, a que se aplica. Schopenhauer considera extremamente importante diferenciar as funções da faculdade de juízo e a da razão, pois, para a produção de conhecimento novo, e para a fundamentação dos saberes já existentes, é da faculdade de juízo que se exige. Se a fundamentação do conhecimento é sempre a sua referência à realidade empírica, ao mundo intuitivo, então, o conhecimento será tanto mais certo quanto mais perfeitamente se conseguir relacionar as intuições aos conceitos, em ambos as direções. A faculdade de razão, por sua vez, apenas opera com juízos relacionando os conceitos que os compõem, segundo os princípios lógicos fundamentais, processo que, segundo Schopenhauer, exige menos poder intelectual do que aquele realizado pela faculdade de juízo. À razão cabe alcançar a conclusão a partir de premissas dadas. Isto significa que o conhecimento produzido pela simples relação de juízos no pensamento dedutivo, racional, não produz nenhum conhecimento que antes já não estivesse contido nas premissas. Este procedimento, apesar de toda a sua importância, que consiste na sistematização da experiência essencial à ciência, não produz nenhum conhecimento novo, e todo o "material" que vem a preencher os conceitos não surge de puros conceitos, mas da intuição, que fornece o estofo para as abstrações do pensamento.

Esta diferenciação é importante para nós no momento porque esta separação entre intuição e pensamento, representação empírica e representação abstrata, possibilita a Schopenhauer manter a noção de identidade pura (ou restrita) que encontramos na primeira formulação da teoria das Ideias de Platão, e que é necessária para sustentar a existência do mundo como representação e uma epistemologia acerca desse mundo. Nossa intenção neste tópico é mostrar que essa herança metafísica platônica, reformulada à luz da filosofia transcendental kantiana, leva a filosofia schopenhaueriana necessariamente a uma concepção petrificada do mundo, que conduz à impossibilidade da liberdade e da felicidade, como também a um determinismo físico, que manifesta a imutabilidade metafísica. Nossa análise, contudo, 
não é apenas negativa, e reconhecemos, com clareza, que mesmo com os possíveis problemas que possam existir na filosofia metafísica de Schopenhauer, sua importância para o pensamento filosófico é inegável, em especial no que se refere à sua influência no surgimento do pensamento psicanalítico. No entanto, mencionamos que é possível abordá-lo de um outro modo, e até mesmo construirmos, a partir de Schopenhauer, uma teoria acerca da prática, e utilizarmos suas teses em questões prementes, presentes no que se refere ao direito e à ética, saindo da pura teorética contemplativa.

Focando, ainda, nos recursos que Schopenhauer utiliza para solucionar o paradoxo da identidade na doutrina das Ideias platônicas, temos agora de perguntar se o próprio Platão já não havia antes recorrido à mesma saída schopenhaueriana, guardadas as particularidades de seu tempo e seu pensamento.

Para Schopenhauer, como já dito acima, as Ideias são conhecidas por intuição. O sujeito, ao contemplar um objeto particular desvinculando seu intelecto em relação ao seu querer, conhece o objeto no que ele tem de essencial, abstraindo as suas propriedades contingentes, e, assim, conhece não mais o fenômeno mas a sua forma universal, aquilo sem o qual o objeto não pode ser o que é, digamos, a sua "determinação" interna infundamentável. No momento da intuição da Ideia, este conhecimento não precisa dos conceitos, não precisa do discurso, da linguagem e de suas formas lógicas. Para ser conhecida, a Ideia não precisa ser dita ou pensada, apenas presenciada. Neste processo de experienciação da Ideia, ela é compreendida por si mesma. Ao tornar-se presente na consciência como modo de ser essencial do fenômeno, seu sentido é apreendido, ou seja, o fenômeno é compreendido. Sua identidade funda-se numa existência anterior e independente do processo lógico regido pelos princípios estruturais da razão, pelos quais a Ideia posteriormente é objeto da linguagem e do discurso, quando então é pensada, reproduzida em conceitos. O pensamento, no sentido estrito do termo, ou seja, o operar com conceitos, é sempre secundário; todo o conhecimento origina-se da experiência intuitiva, processo realizado pelo entendimento, faculdade pela qual o mundo empírico é constituído como 
representação. Como nos diz Schopenhauer, a razão não gera, apenas concebe, pois é de natureza "feminina"; apenas recebe aquilo que provém do entendimento, abstrai destes conteúdos materiais tudo aquilo que lhe é acessório, e, assim, remonta em abstrato à universalidade da Ideia que foi "esfacelada" na pluralidade dos fenômenos.

As Ideias, atos imediatos da Vontade (coisa-em-si), seus modos determinados, que não podem ser compreendidos senão por si mesmos na intuição, não são, como suas objetivações materiais, os fenômenos, algo relativo, que vêm a ser apenas pelas relações que o determinam. A relatividade e contraditoriedade dos conceitos, por sua vez, provêm do fato de eles espelharem a pluralidade de Ideias que se objetivam em um único fenômeno, que ao ser expresso na linguagem é dito por diversos predicados, fazendo com que o sujeito seja uma unidade múltipla, justamente aquilo que nos Diálogos platônicos se mostra como problema ontológico, já que a linguagem expressa o Ser ordenado logicamente.

Como vimos, em Schopenhauer, a contraditoriedade é de natureza apenas lógica e não ontológica; afeta apenas os conceitos, que são de natureza racional, não as /deias, objetos da intuição que estão aquém das formas particulares do princípio de razão. A "natureza" racional das Ideias em Platão, e sua contraditoriedade, é justamente o que leva ao problema ontológico, pela impossibilidade de fundamentar a identidade na pura razão, e a correspondência necessária que deve haver entre a alma e o mundo. Tendo em mente a grandeza do gênio de Platão, é bastante provável que, diante das dificuldades apresentadas pela natureza lógica das Ideias, ele tenha procurado alternativas para superar o problema da contradição que invade o plano ontológico. 0 que o levaria a considerar essa realidade essencial como algo de uma natureza tal, e em um nível tão fundamental, que seja alheia à própria razão. No entanto, isso traz uma quebra na correspondência entre a natureza racional da alma e o Ser (realidade inteligível), que a princípio partilham de um mesmo logos, e este é um inconveniente tão importante e problemático quanto a contradição lógica. A quebra da identidade entre alma e mundo, no contexto da filosofia platônica, levaria à incognoscibilidade do próprio mundo, decretaria um ceticismo epistemológico, o que talvez fosse inaceitável 
para Platão. A consideração de uma razão objetiva, ou seja, de que o mundo é em si mesmo racional, parece conduzir a caminhos sempre aporéticos. De fato, encontramos interpretações da filosofia platônica que conduzem à uma incognoscibilidade e, deste modo, à irracionalidade, do plano mais fundamental da existência. Neste sentido parece caminhar a interpretação dos que partilham das hipóteses da escola de Tünbingen, que giram em torno das doutrinas não escritas. Uma discussão mais pormenorizada desta questão exigiria, como já dito, uma exegese que escapa aos objetivos e possibilidade do presente trabalho. De qualquer modo, entendemos que Schopenhauer percebe na teoria platônica a permanência da tese de que as Ideias, o Ser em sentido estrito, são de natureza lógica, racional.

Contudo, temos ainda de colocar a questão: o conhecimento das Ideias, em Platão, já não teria sido formulado de um modo análogo ao que em Schopenhauer é a intuição, enquanto conhecimento não lógico? Bem, dentre outras possíveis interpretações, está presente na interpretação de Manfredo Oliveira a tese de que as Ideias são conhecidas por um modo de conhecimento não linguístico, independente da palavra e do discurso e, neste sentido, não racional, se entendemos, como Schopenhauer, que a atividade da razão é indissociável de um processo discursivo, e que apesar do conceito ser "por inteiro diferente tanto da palavra, a qual está conectado, quanto das intuições, das quais originou-se"18, ainda assim, “o conceito é uma representação, cuja consciência distinta e conservação ligam-se à palavra, por isso os gregos designavam palavra, conceito, relação, pensamento com o nome da primeira:

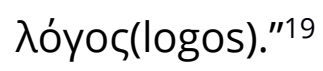

Portanto, para que os conceitos se façam presentes na consciência, ou seja, para serem pensados, precisam ser representados pelos seus signos sensíveis, as palavras. Se é assim, um conhecimento não linguístico, ou seja, não discursivo, é não racional, e nos remete ao que para Schopenhauer é a intuição. Na passagem abaixo vemos como

\footnotetext{
${ }^{18}$ SCHOPENHAUER, 0 mundo como vontade e como representação, Segundo tomo, 76.

19 Ibidem, 75.
}

Voluntas, Santa Maria, v.12, n.1, p. 01-30, jan/abril, 2021 
Manfredo expressa a hipótese de que o conhecimento das Ideias independe da linguagem.

\begin{abstract}
Mas há em todas essas discussões, afirmações muito mais graves, que nos manifestam o que Platão pensa, em última análise, sobre a linguagem humana. Se os nomes podem ser verdadeiros ou falsos, argumenta Platão, e se temos a possibilidade de decidir sobre isso, então deve haver algo que nos revela, sem os nomes, que nomes são verdadeiros ou não. É possível, portanto, conhecer as coisas sem os nomes. Aqui está a tese fundamental de Platão e de toda filosofia do Ocidente: ele pretende, com essa discussão das diferentes teorias vigentes de seu tempo, mostrar que na linguagem não se atinge a verdadeira realidade (alétheia ton onton) e que o real só é conhecido verdadeiramente em si (aneu ton onomaton) sem palavras, isto é, sem a mediação linguística. A linguagem é reduzida a puro instrumento, e o conhecimento do real se faz independente dela. O puro pensar, a contemplação das Ideias, é para Platão um diálogo sem palavras, da alma consigo mesma (Sofista, 263 d). A linguagem não é, pois, constitutiva da experiência humana do real, mas é um instrumento posterior, tendo uma função designativa: designar com sons o intelectualmente percebido sem ela. Sua tese fundamental é a distinção radical entre pensamento e linguagem, sendo esta reduzida à expressão secundária ou a instrumento (organon) do pensamento. (...). O pensar é uma atividade essencialmente nãolinguística e, sendo assim, a relação da linguagem para o real é secundária. ${ }^{20}$
\end{abstract}

Mas o que seria esse "diálogo sem palavras, da alma consigo mesma", pelo qual contemplamos e conhecemos as Ideias? Esse acesso imediato à verdadeira realidade, de que nos fala Manfredo, considerando que esta seja o plano inteligível das Ideias, corresponde ao que em Schopenhauer nomeia-se intuição. Aceitando esta hipótese acerca do conhecimento das Ideias platônicas, e abstraindo da teoria schopenhaueriana - apenas para pensar esse paralelo - a dimensão transcendental da filosofia da natureza de Schopenhauer que entende as Ideias não como o Ser (coisaem-si), mas como objetivação imediata deste, que diferencia-se apenas por já ser representação, então, dizíamos, as filosofias em questão teriam de fato grande proximidade, no que diz respeito a este recorte de suas doutrinas, e não haveria grande novidade no procedimento schopenhaueriano em considerar o acesso às Ideias independente da linguagem, e, portanto, independente da razão. Mas, se de fato, para Platão, as Ideias são conhecidas por uma faculdade não linguística, portanto não lógica, o que é muito estranho, por que então considerar as contradições da linguagem um

20 OLIVEIRA, Reviravolta Linguístico-pragmática na Filosofia Contemporânea, 22.

Voluntas, Santa Maria, v.12, n.1, p. 01-30, jan/abril, 2021 
problema tão grande que fosse necessário transformar a teoria ontológica e reformular nos Diálogos tardios a teoria das Ideias, aproximando sua estrutura constitutiva da estrutura relativa do plano sensível, o que trouxe também sérios problemas? E como pensar um diálogo sem palavras, se por palavra considerarmos nada mais que um signo, que no caso é sonoro, mas que pode ser expresso também de outro modo? Entendemos que uma ação ou atividade possa ser não-linguística, e que possa posteriormente ser comunicada linguisticamente, mas não entendemos como pode ocorrer um diálogo ou discurso sem a mediação do seu signo linguístico, que quando expresso em sons é a palavra, mas que pode ser também expresso por outros meios físicos.

Na verdade, a passagem mencionada no Diálogo Sofista nos fala de um diálogo "silencioso", o que não significa sem linguagem, pois os signos linguísticos podem ser outros que não os sons articulados: "Pensamento e discurso são, pois, a mesma coisa, salvo que é ao diálogo interior e silencioso da alma consigo mesma, que chamamos pensamento" 21 . Se, para Platão, "pensamento" e "discurso" são o mesmo, e todo discurso ou diálogo se dá linguisticamente, não podemos aceitar a tese de que há, em Platão, uma "distinção radical entre pensamento e linguagem". A correspondência existente entre a natureza racional do Ser e a razão presente na alma, esta que é parte do ser e compartilha sua natureza, é o motivo da reformulação tardia da teoria das Ideias em Platão, que expõe com clareza a sua estrutura aporética.

O pensamento em sentido estrito, ou seja, o raciocínio, é, por definição, segundo Schopenhauer, uma operação linguística, na qual os objetos processados, os conceitos, para serem acessados pela consciência, precisam ser representados por signos, dentre eles os sons articulados a que chamamos palavra. Os conceitos, entidades lógicas da razão, precisam de um meio sensível para se tornar presentes para a consciência. Como explica Schopenhauer, a natureza temporal da consciência individual exige como condição de existência de qualquer objeto ou qualquer representação, que esta seja

${ }^{21}$ PLATÂO. Sofista, 263 e.

$\overline{\text { Voluntas, Santa Maria, v.12, n.1, p. 01-30, jan/abril, } 2021}$ 
inserida no fluxo do tempo, para que assim se torne presente. No caso dos conceitos estes são gerados a partir da intuição, se constituindo em abstrações da experiência. Para que conceitos sejam invocados e se façam presentes na consciência é necessário que eles sejam vinculados a um signo sensível, uma intuição, que thes conceda objetividade. Este signo, no caso da linguagem articulada humana, é a palavra.

Eis porque, para entrarem no presente imediato de uma consciência individual, portanto, serem inseridos numa série temporal, eles têm de poder ser como que reconduzidos à natureza das coisas singulares, como que individualizados e, por conseguinte, vinculados a uma representação sensível: a palavra. Esta é, por conseguinte, o signo sensível do conceito e como tal o meio necessário que o FIXA, isto é, presentifica-o na consciência, inseparável da forma temporal, e assim estabelece uma ligação entre a razão, cujos objeto são meras e gerais universalia que não conhecem lugar nem tempo, e a consciência, inseparável do tempo, sensível e nessa medida meramente animal. ${ }^{22}$

Segundo Schopenhauer, o pensamento precisa sempre ser apoiado, ora por palavras, ora por imagens da fantasia. No entanto, o pensamento em sentido estrito é a atividade da razão e da faculdade de Juízo, que, como já dito, consiste em operar com conceitos. A simples presença de imagens na mente, tenham estas fundamento na experiência ou sejam puras quimeras, "fantasmas", construídas pela imaginação, sem correspondente objeto real, não constituem pensamento no sentido próprio do termo. Este requer signos que não sejam eles mesmos imagens da imaginação, mas apenas simbólicos, como as "palavras". Por quê? Simplesmente porque o conceito é uma representação abstrata, que enquanto tal mantém em seu significado apenas o essencial do objeto a que se refere, e justamente por isso, pela abstração das propriedades contingentes do fenômeno individual a partir do qual surge, pode abarcar em si uma multiplicidade de fenômenos. Toda imagem por sua vez, por mais imprecisa que seja, carrega consigo uma série de particularidades que impedem a função de representante universal, que apenas significantes meramente simbólicos e

22 SCHOPENHAUER, O mundo como vontade e como representação, Segundo tomo, 78.

Voluntas, Santa Maria, v.12, n.1, p. 01-30, jan/abril, 2021 
não imagéticos podem exercer. Estes são as palavras, sejam em sua representação sonora ou visual. É claro que a "palavra", em sentido estrito, define-se pela sua representação sensível como som articulado; no entanto, num diálogo silencioso como o que Platão menciona no Sofista, que é justamente o que define o "pensamento", este consiste na lembrança do seu signo sensível. Quando pensamos nenhum som é proferido, mas as palavras também se tornam presentes pela memória de seu signo, que é invocando apenas mentalmente, como entidade lógica operada pela razão. Entretanto, mais correto seria se Schopenhauer utilizasse em lugar do termo "palavra" apenas o termo signo. O conceito "palavra" traz consigo em sua definição a "representação sonora" dentre seus predicados, mas sabemos que uma palavra também pode ser representada por um símbolo visual, que também é um significante sensível, mas que enquanto tal não coincide completamente com a definição do conceito "palavra" tal como mencionamos. Surdos desenvolvem a capacidade linguística e a representação dos signos necessários, que no caso são apenas visuais (mas também poderiam ser táteis), sem associação ao som, no entanto dizemos que são palavras. Assim, ou retiramos do conceito "palavra" o atributo "expressão sonora", o que seria muito contrário ao seu conceito, fazendo do termo um sinônimo de "signo", ou dizemos que a linguagem é indissociável não da palavra propriamente mas dos signos, dos quais a palavra é apenas um tipo. No lugar de dizer, com Schopenhauer “Palavra e linguagem, portanto, são os instrumentos indispensáveis para o pensamento distinto"23, diremos "signo e linguagem ...". O que deixaria mais claro o que ele quer dizer na seguinte passagem:

Às vezes decerto ocorre que conceitos ocupem a consciência sem seus signos, na medida em que ocasionalmente passamos em revista de modo tão rápido uma cadeia dedutiva que, nesse tempo, não pudemos pensar nas palavras. Mas essas são exceções que justamente pressupõem um grande exercício da razão, que ela só pôde conseguir mediante a linguagem. O quanto o uso da razão está vinculado à linguagem, vemo-lo no caso dos surdos-mudos, os quais, se não aprendem nenhum tipo de linguagem, dificilmente mostram mais inteligência que os orangotangos e elefantes: pois tem faculdade de razão apenas potentia não $a c t u .^{24}$

\footnotetext{
${ }^{23}$ SCHOPENHAUER, 0 mundo como vontade e como representação, Segundo tomo, 79.

${ }^{24}$ SCHOPENHAUER, $\mathbf{O}$ mundo como vontade e como representação, Segundo tomo, 79.
}

Voluntas, Santa Maria, v.12, n.1, p. 01-30, jan/abril, 2021 
Nesta citação temos que mencionar dois pontos. Primeiro, esclarecer que o que Schopenhauer quer dizer quando afirma que "às vezes decerto ocorre que conceitos ocupem a consciência sem seus signos" não é que seja possível pensar, ou seja, relacionar conceitos, desvinculados dos seus signos linguísticos, mas simplesmente que para uma razão treinada e ágil, esse processo de manipulação se torna tão rápido e natural, fluido, que a consciência já não precisa focar nas palavras (signos), que tornam-se praticamente imperceptíveis, tal é o grau de automatização do processo de raciocínio. Isto fica bastante claro na continuação do parágrafo, quando o vemos dizer "na medida em que ocasionalmente passamos em revista de modo tão rápido uma cadeia dedutiva que, nesse tempo, não pudemos pensar nas palavras", e nos diz que são exceções alcançadas unicamente pelo exercício da razão mediante uso da linguagem. Segundo, o modo como enfatiza "o quanto o uso da razão está vinculado à linguagem", o que explicita a tese schopenhaueriana de que a razão é simplesmente uma faculdade lógica, que não participa do processo de intuição e que, portanto, não é geradora de conhecimento e não condiciona o conhecimento das /deias, mas apenas remonta à sua unidade e universalidade em representações abstratas.

A separação schopenhaueriana entre representações intuitivas e representações abstratas afasta das Ideias as contradições do âmbito lógico, pertencentes à razão e à sua atividade, o pensamento. As aporias da linguagem não alcançam a realidade intuitiva e suas identidades autodeterminadas. O realismo platônico, no entanto, exige que a lógica do pensamento não seja apenas um processo mental, mas que corresponda à realidade objetiva; "tem de haver" um isomorfismo entre linguagem e mundo, uma correspondência de estrutura que expressa a organização lógica do próprio Ser, sujeitando este aos problemas da linguagem. Esta natureza lógica do Ser platônico parece ser o que conduz a todas as dificuldades da sua metafísica.

Deste modo, pensamos, Schopenhauer acredita salvar as identidades constitutivas do mundo como representação e necessárias ao processo de pensamento. O princípio de individuação (tempo, espaço e causalidade), apenas rege a ordem de aparição das qualidades, forças e espécies, e sua aparência fenomênica, que 
mostram-se para a consciência como múltiplos indivíduos. Indivíduos estes que, do ponto de vista da coisa-em-si, segundo nosso filósofo, são, para além do véu de Maia, para além da aparência da individualidade, uma única e indivisa coisa, compreendida sob o nome Vontade. No contexto de sua metafísica, apesar das vacilações neste sentido, não haveria individualidade na perspectiva da coisa em si mesma, já que, como sabemos, a individuação está condicionada às formas do sujeito, sendo, portanto, do âmbito da representação. Contudo, não está claro até que ponto a individualidade enraíza-se ${ }^{25}$ além das formas da representação, pois o próprio Schopenhauer abre brechas neste sentido, e tal questão não fica clara. Mas se as /deias não são indivíduos, mas realidades metafísicas universais, elas são, contudo, identidades. Mesmo que essas identidades, em sentido estrito, não possam ser conhecidas em si mesmas, a simples existência fenomênica de uma multiplicidade de qualidades empíricas atesta a realidade múltipla e oculta que há também do lado do em-si, ou pelo menos assim mostra-se a nós. Como conciliar a unidade da Vontade com a multiplicidade dos modos de querer, que são as Ideias, é um problema ao qual Schopenhauer parece não ter dado tanta atenção, e sobre o qual ele mesmo diz talvez ser insolúvel, devido à própria limitação da capacidade humana de conhecimento. Como ele mesmo nos diz, nunca pretendeu responder todas as questões.

A herança platônica das identidades puras na metafísica da natureza de Schopenhauer e sua fusão com o idealismo transcendental kantiano tem importantes consequências para o restante do seu "sistema", que se pretende expressão de um pensamento único, em especial a sua ética, considerada não apenas indissociável da metafísica da natureza mas o ápice do seu sistema metafísico.

\footnotetext{
25 "Ademais, pode-se perguntar, quão fundo, na essência em si do mundo, descem as raízes da individualidade?, ao que se poderia em todo caso responder: elas descem tão fundo até onde alcança a afirmação da vontade de vida; onde a negação da vontade entra em cena, elas param: pois elas brotam com a afirmação." (SCHOPENHAUER, O mundo como vontade e como representação, Segundo tomo, 764).
}

Voluntas, Santa Maria, v.12, n.1, p. 01-30, jan/abril, 2021 


\section{REFERÊNCIAS}

GOLDSCHMIDT, V. Os diálogos de Platão: estrutura e método dialético. São Paulo: Edições Loyola. 2002.

KANT, I. Crítica da Razão Pura. São Paulo: Abril Cultural, 1980.

PLATÃO. Mênon. Trad. Maura Iglésias. Rio de Janeiro: Ed. PUC-Rio: Loyola, 2001.

PLATÃO. Sofista. Trad. José Cavalcante de Souza, Jorge Paleikat e João Cruz Costa. São Paulo: Abril Cultural, 1983.

REALE, G. Para uma nova interpretação de Platão. Trad. Marcelo Perine. São Paulo: Edições Loyola, $2^{a}$ edição, 2004.

SCHOPENHAUER, A. Sämtliche Werke. Editadas e comentadas por Wolfang Frhr. von Löhneysen. Suhrkamp taschenbuch wissenschaft, 2003.

SCHOPENHAUER, A. O mundo como vontade e representação. Trad. M. F. Sá Correia. Rio de Janeiro: Contraponto, 2001.

SCHOPENHAUER, A. O mundo como vontade e como representação. Trad. Jair Barboza. São Paulo: Unesp, 2005.

SCHOPENHAUER, A. O mundo como vontade e como representação, Segundo tomo: suplementos aos quatro livros do primeiro tomo. Trad. Jair Barobosa. I. ed. São Paulo: Editora Unesp, 2015.

SCHOPENHAUER, A. Crítica da filosofia kantiana. Trad. Maria Lúcia M. O. Cacciola. São Paulo: Nova Cultural Ltda. 1999.

\section{Contribuição de autoria}

\section{1 - Francisco William Mendes Damasceno}

Filósofo, Doutor em Filosofia

https://orcid.org/0000-0001-5920-8314•williammendesg@gmail.com

Contribuição: Escrita - Primeira Redação

\section{Como citar este artigo}

DAMASCENO, W., M., Francisco. A busca schopenhaueriana das identidades fundamentais: a influência platônica. Voluntas Revista Internacional de Filosofia, Santa Maria, v 12, n. 1, e11, 2021. DOI 10.5902/2179378661899. Disponível em: https://doi.org/10.5902/2179378661899. Acesso em: dia mês abreviado. ano. 